\title{
LA GESTIÓN COLECTIVA DE LOS CONTRATOS EN ORIGEN DE TEMPOREROS COLOMBIANOS EN LA PROVINCIA DE LLEIDA ${ }^{1}$
}

\author{
Mercedes Gordo Márquez \\ Universidad de Huelva \\ mercedes.gordo@dhis2.uhu.es \\ Rafael Allepuz Capdevila \\ Universidad de Lleida \\ rafael.allepuz@econap.udl.cat \\ Juan Antonio Márquez Domínguez \\ Universidad de Huelva \\ antonio@uhu.es \\ Teresa Torres Solé \\ Universidad de Lleida \\ torres@econap.udl.cat
}

\section{RESUMEN}

Las condiciones de trabajo y el carácter cíclico del sector primario dio como resultado la falta de mano de obra para atender diversas tareas, haciéndose necesario un procedimiento de contratación de temporeros extranjeros en su país de origen. El trabajo analiza la implantación de estos contratos para la agricultura en la provincia de Lleida y su evolución hasta la actualidad. Se presta especial atención a las preferencias mostradas en cuanto a la nacionalidad, que se concreta en el reclutamiento de jornaleros colombianos. Se abordará el por qué de ello y el perfil del trabajador contratado.

Palabras clave: contrataciones en origen de temporada, control de los flujos migratorios, temporeros colombianos, agricultura, Lleida.

Fecha de recepción: abril 2013.

Fecha de aceptación: marzo 2014.

1 Este artículo recoge parte del trabajo realizado por los autores en la ejecución del proyecto I+D+i Gestión colectiva de contrataciones agrícolas en origen y sus soportes territoriales en España y Marruecos: propuesta de concatenación de campañas e implicaciones en el codesarrollo. Dicho proyecto es financiado por el Ministerio de Ciencia e Innovación (Ref. CSO2010-18764, 2011 - 2014) y está siendo llevado a cabo por investigadores de distintas universidades españolas. El «Instituto de Desarrollo Local» (IDL), grupo de investigación de la Universidad de Huelva, actúa como jefe de filas del mismo. 


\section{ABSTRACT}

The working conditions and the cyclical nature of the primary sector resulted in the lack of manpower to meet a variety of tasks, making the recruitment of foreign seasonal workers in their country of origin necessary. The paper analyzes the implementation of these contracts for the agriculture in the province of Lleida and its evolution to the present. Special attention is paid to the preferences shown in terms of nationality, as embodied in the recruitment of Colombian labourers. The reason for it and the profile of the contract worker will be addressed.

Keywords: Temporary contracting in origin, control of migration flows, agrarian temporary workforce from Colombia, agriculture, Lleida.

\section{INTRODUCCIÓN}

El desarrollo socioeconómico experimentado en España a lo largo del siglo XX, en particular desde su adhesión a la Unión Europea, dio como resultado una mejora en la formación y cualificación de los efectivos laborales. Esto ha favorecido que en la incorporación al mercado de trabajo se haya producido una tendencia a ocupar puestos en la industria y los servicios, en detrimento del sector primario, rechazado por las condiciones de trabajo que ofrece: carácter cíclico, menor consideración social, en ocasiones sueldos más bajos, etc. La situación descrita dio como resultado que a principios de los años noventa del siglo XX existiera una carencia de trabajadores para atender las diversas tareas generadas en el campo, en particular las más intensivas en el uso de la mano de obra, como son la recolección de las cosechas y su manipulado agroindustrial. A fin de atender las necesidades laborales de los agricultores se articuló un procedimiento específico de contratación de temporeros extranjeros en sus países de origen, al cual se recurre sólo cuando la situación nacional de empleo lo hace necesario, es decir, cuando la incorporación de nuevos efectivos laborales no suponga una competencia para el jornalero español ni para otros extranjeros ya residentes en el país que legalmente puedan trabajar, sean nacionales de la Unión Europea o de terceros países. Este procedimiento se encuentra actualmente incluido en la Ley y Reglamento de Extranjería bajo la expresión gestión colectiva de las contrataciones en origen.

Los empresarios de la fruticultura leridana fueron quienes llevaron a cabo las primeras experiencias piloto de este sistema de contratación, concretamente en 1999. Hoy son, tras los agricultores de la provincia de Huelva, los que más jornaleros reclutan por esta vía. Así, el presente trabajo analiza la implantación de los contratos en origen de temporada para la agricultura en la provincia de Lleida y su evolución hasta la situación actual, donde el contexto socioeconómico que atraviesa España, caracterizado por un elevado desempleo, ha llevado a reducir considerablemente los cupos autorizados. La investigación también presta especial atención a las preferencias mostradas por estos empresarios catalanes en cuanto a la nacionalidad de la mano de obra, la cual se concreta, de manera importante, en el reclutamiento de jornaleros colombianos. Se aborda el por qué de ello y el perfil del trabajador contratado, atendiendo a variables como el sexo, edad, estado civil y su carácter repetidor o no en la campaña. 
Tras el apartado metodológico, el trabajo se centra en el análisis de los antecedentes que muestran el por qué surgió en Lleida la necesidad de contratar jornaleros extranjeros en sus países de origen, dedicándose el cuarto punto a abordar la implantación de este procedimiento de contratación. A continuación, en el apartado quinto, se analiza el perfil de estos trabajadores, destacando el peso y las causas por las que los empresarios de la fruticultura leridana se han decantado por Colombia como cantera laboral. El sexto punto analiza cómo el nuevo escenario económico ha modificado las contrataciones en origen. Por último, se recogen las conclusiones del trabajo y la bibliografía.

\section{METODOLOGÍA}

Para alcanzar el objetivo propuesto se ha recurrido a diversas técnicas metodológicas. El punto de partida fundamental ha sido la información facilitada por la Dependencia Provincial de Trabajo e Inmigración de la Subdelegación del Gobierno en Lleida, el análisis de la normativa generada para regular estos contratos y la revisión de diversas estadísticas oficiales, informes técnicos y bibliografía. Esta labor se ha complementado con un trabajo de campo apoyado en entrevistas a los agentes implicados, para tener en cuenta las opiniones de empresarios, sindicatos y la Administración.

Las entrevistas se iniciaron en el año 2007 en el marco del proyecto «Eficacia de la contratación en origen para la inserción laboral de la población extranjera en Cataluña. Aportaciones para un debate», estudio concedido por la Agencia de Gestión de Ayudas Universitarias y de Investigación de la Generalitat de Cataluña, del cual son investigadores dos de los autores. Posteriormente, el trabajo de campo se desarrolló durante las campañas de recolección de 2011 y 2012 en el marco del proyecto de I+D+i financiado por el Ministerio de Ciencia e Innovación (Ref. CSO2010-18764, 2011 - 2013) «Gestión colectiva de contrataciones agrícolas en origen y sus soportes territoriales en España y Marruecos: propuesta de concatenación de campañas e implicaciones en el codesarrollo», del cual forman parte los autores del presente trabajo.

\section{LA NECESIDAD DE JORNALEROS EN LA AGRICULTURA}

En Cataluña, así como en el resto de España, el modelo tradicional que consideraba a la familia como unidad de producción agraria fue desplazado por una nueva estructura agraria, caracterizada por la presencia de explotaciones pequeñas totalmente intensivas. La transformación hacia este modelo estuvo acompañada de una paulatina disminución de la población agraria, debido a la desaparición de aquellas explotaciones que no se adaptaron al nuevo sistema. No obstante, la superficie cultivada continuaba manteniendo su tamaño, con lo cual las explotaciones agrarias ganaron dimensión e implantaron un sistema de producción intensivo para ganar eficiencia a través de una mayor productividad. El aumento de la productividad del suelo se consiguió también a través de la expansión de las zonas de regadío y el cultivo de nuevos productos, en Lleida concretamente la fruta dulce. Esta modernización del sector facilitó la incorporación de la producción agraria catalana en el comercio internacional.

Ante la necesidad de mano de obra remunerada para llevar a cabo las actividades en la explotación, la estructura productiva de la agricultura moderna introdujo el factor trabajo 
como un elemento más del proceso productivo. Éste viene siendo especialmente importante en el sector de la fruta, debido a la mayor dificultad en mecanizar su proceso de recolección.

¿De dónde se obtenían los efectivos laborales? Tradicionalmente, cuando llegaba la época de la recolección era la familia entera de la explotación la que la recolectaba: los abuelos, los jóvenes y los más pequeños de la casa crecían entre cubo y cubo de fruta. Los estudiantes aprovechaban la campaña de recolección para conseguir unos ingresos con los que pagarse los estudios. También llegaban familias de Andalucía, Extremadura o las regiones castellanas, que cada año solían ser las mismas. Incluso algún municipio llegó a cambiar la fecha de la fiesta local porque, con la introducción de los cultivos de fruta, la festividad coincidía con la época de más trabajo en el campo, la recolección de la fruta (Cabré, 2010). La poca cualificación, bajo salario y elevada temporalidad provocó que determinados colectivos en situación de exclusión social, como el caso de los gitanos, llegaran a especializarse en la recogida de estos productos (fruta dulce, uva, aceituna), encontrando en estas tareas un nicho laboral (Achón, 2011).

No obstante, la contratación de este tipo de jornaleros iba acompañada de cierta incertidumbre por parte del agricultor, al ser una mano de obra inestable. A la misma conclusión llega el trabajo de Achón (2011), los estudiantes eran una mano de obra volátil, dada la concepción que tenían del trabajo temporero, lo que incidía en su baja permanencia respecto a la necesidad del agricultor. Los trabajadores en paro venidos de otras regiones representaban una alternativa oportuna para garantizarse la estabilidad laboral durante la campaña. Sin embargo, la aprobación de sistemas especiales para protegerlos incidió negativamente en su permanencia en los tajos. Así, los Planes de Empleo Rural aprobados a partir de 1984 tenían como eje central un subsidio por desempleo a favor de los trabadores eventuales incluidos en el Régimen Especial Agrario de la Seguridad Social. Una vez que estas personas completaban el número de peonadas suficientes para acceder al cobro de dicho subsidio, un total de 60 jornadas, abandonaban las tareas de recolección. Estas «deserciones» se justifican no sólo por la dejadez de los trabajadores, sino muy especialmente porque el hecho de seguir trabajando hacía que aumentaran sus ingresos «declarados», oficiales, de manera que podían quedar excluido de percibir el subsidio.

En este contexto, las empresas agrarias tenían dificultades para contratar trabajadores con garantías de estabilidad a lo largo de la campaña, puesto que los salarios y las condiciones de trabajo que ofrecían no eran lo suficientemente atractivas para la mano de obra disponible, a pesar de las altas tasas de paro, que superaron el 15\% durante la década de los ochenta del siglo XX (Etxezarreta, 1994). Sin embargo, al igual que sucedió en otras geografías españolas, como la provincia de Huelva (Gordo, 2009; Díaz, 2009), apareció otro colectivo al que sí le interesó trabajar en esas condiciones. Eran los inmigrantes extranjeros que a finales de los años ochenta del siglo XX habían llegado a España procedentes del norte de África y de la zona subsahariana. De esta forma se inició un proceso laboral de reemplazo en el que los jornaleros extranjeros llenaron el vacío que generó el abandono de la agricultura por parte de los trabajadores nacionales, que se insertaron en otros sectores con mejores condiciones sociolaborales.

En general, la contratación de estos inmigrantes se caracterizaba por la inexistencia de un contrato formal, al amparo de una débil actuación del Ministerio de Trabajo en materia de inspección. Esta relajación en la vigilancia de las normas generaba una indefensión del 
trabajador sujeto a un sistema laboral que remuneraba las horas trabajadas por debajo de lo aprobado en el convenio colectivo, incluidas las horas extras, imponía excesivas jornadas laborales y no cumplía con la afiliación a la Seguridad Social. Estas condiciones caracterizaron el trabajo agrícola como un trabajo de escasa consideración social (Achón, 2011; Gordo, 2011). Aún así los jornaleros extranjeros accedieron a estos nichos laborales sobre todo por las dificultades para acceder a otros puestos de trabajo. Las tareas en el campo les suponía una ocupación rápida y les permitía o bien una primera fuente de ingresos, o bien unos ingresos económicos que compatibilizaban con otras actividades a lo largo del año.

El número de extranjeros que desarrollaban estos trabajos agrícolas creció año tras año, lo cual agudizó la precariedad social y jurídica de este colectivo. Ante esta situación, Unió de Pagesos, el principal sindicato agrario de Cataluña, tomó la iniciativa y se posicionó como prestador de un servicio de intermediación laboral para la contratación de extranjeros que tuvieran su documentación en regla, al tiempo que prohibió a sus afiliados efectuar contrataciones a extranjeros en situación de irregularidad administrativa. Además, en el período 1985-1992 inició la proyección de una pequeña red de alojamientos con el objetivo de que los trabajadores disponibles circulasen a través de ella al ser contratados por los distintos empresarios agrícolas. A partir de 1992 el sindicato continuó su proyecto para consolidar el sistema de distribución de trabajadores con la creación de nuevos alojamientos en la provincia de Lleida. Posteriormente se produjeron los primeros acuerdos de gestión de alojamientos entre Unió de Pagesos y algunos ayuntamientos ${ }^{2}$.

A partir de 1996 la Consejería de Agricultura del gobierno catalán, que había contribuido financieramente a la ampliación de la red de alojamientos, redujo sus ayudas. Desde entonces Unió de Pagesos potenció la contratación de temporada en aquellas explotaciones en las que el agricultor ofrecía un alojamiento. En este sentido hay que aclarar que la mayor parte de albergues se habían construido en las comarcas del Segrià (importante fuente de producción de fruta dulce), Urgell (con predomino de la vendimia) y el Pla d'Urgell (también con fruta dulce).

Paralelamente, el crecimiento de la economía catalana iniciado al amparo de la entrada en la Unión Europea favoreció, en una primera etapa, la creación de empleo en el ámbito industrial. Posteriormente el factor de crecimiento económico se centró en el despegue de la construcción, hasta el punto de que el 46,2\% de los nuevos puestos de trabajo creados en Cataluña en el período 2001-2006 correspondían a este subsector según datos del Instituto Nacional de Estadística. El modelo de crecimiento económico en esos años se basó en la posibilidad de crear empleo en actividades de poco valor añadido, no sólo en la construcción, también en determinadas actividades del sector servicios, como el comercio o las relacionadas con el turismo. Esto dificultó el crecimiento de la productividad, a la vez que favoreció las posibilidades de llegada de población extranjera más dispuesta a trabajar en estos empleos, cuyos salarios eran muy atractivos (Allepuz et al., 2009a). Asimismo, muchos de los extranjeros contratados como temporeros agrarios empezaron a causar baja en el campo al ser ocupados en los empleos que se generaban en la construcción y servicios, amenazando la continuidad de la actividad agrícola. De esta forma la falta de mano de obra temporal se

2 Véase el trabajo de Achón (2011) para una mayor información sobre el sistema de alojamiento de trabajadores extranjeros en la zona de Lleida. 
volvió cada vez más acuciante para los empresarios agrícolas e hizo necesario buscar una solución, sobre todo a medida que la superficie cultivada aumentaba y se introducían variedades más productivas.

\section{LOS CONTRATOS EN ORIGEN DE TEMPOREROS EXTRANJEROS}

La respuesta ante la falta de mano de obra en las actividades agrícolas fue su importación como un input más del ciclo productivo. Para ello se articuló un procedimiento que permite canalizar los flujos migratorios hacia estas ocupaciones. El primer paso en esta dirección se dio a raíz de la Proposición no de Ley relativa a la situación de los extranjeros en España, presentada el 9 de abril de 1991 al Congreso de los Diputados. En ella, entre otras medidas, se encomendaba al Gobierno «desarrollar una política activa de inmigración en la que los poderes públicos, con el amplio respaldo de las fuerzas políticas y sociales, tomen la iniciativa en la canalización y organización de los flujos de inmigración legal en función de las necesidades de mano de obra de la economía española y de la capacidad de absorción de nuestra sociedad». En cumplimento de este compromiso el Consejo de Ministros adoptó a partir de 1993 la política del contingente, la fijación anual del número de trabajadores extranjeros no comunitarios a los que se les permite entrar en España para trabajar.

Desde un primer momento se trató de evitar la competencia laboral que podría suponer la entrada de estos nuevos efectivos laborales. Así, el Preámbulo de la Resolución que dictaba las instrucciones generales del contingente para $1993^{3}$ dejaba claro que este procedimiento debía «garantizar la preferencia de la mano de obra española, comunitaria y extranjera legalmente residente en nuestro país, para atender en primera instancia aquellas ofertas de empleo que en cada caso se produjesen». Al mismo tiempo, insistía: «en ningún caso se presenta el contingente como una medida encaminada a incentivar la inmigración hacia nuestro país, sino que [...] se trata de una actuación que persigue la canalización y control de los flujos migratorios, facilitando un número máximo de autorizaciones que únicamente se irán utilizando si el mercado de trabajo nacional no es capaz de satisfacer las necesidades empresariales de forma adecuada. Ello con el fin de evitar que dichas necesidades se atiendan de forma irregular y de combatir la explotación de inmigrantes y la irregularidad en la contratación por las empresas».

El contingente, tal y como estaba diseñado, no conseguía responder a las necesidades de los agricultores, entre otras cuestiones porque no tenía en cuenta las especificidades de estas actividades, entre ellas la temporalidad y la necesidad de agilidad en la tramitación de los contratos (Gordo, 2009). Para hacer frente al problema, el 17 de diciembre de 1997 se reunieron en Madrid el Ministerio de Trabajo y Asuntos Sociales, la Asociación Agraria de Jóvenes Agricultores (ASAJA), la Coordinadora de Organizaciones de Agricultores y Ganaderos (COAG), la Federación de Trabajadores de la Tierra del sindicato Unión General de Trabajadores (UGT), la Federación Estatal del Campo del sindicato Comisiones Obreras (CCOO)

3 Resolución de 14 de junio de 1993, de la Subsecretaría del Ministerio de Relaciones con las Cortes y de la Secretaría del Gobierno, por la que se dispone la publicación de la de 4 de mayo de 1993, por la que se dictan instrucciones generales y de procedimiento sobre determinación de un contingente de autorizaciones para trabajadores extranjeros para 1993, conjunta de los Directores generales de Asuntos Consulares, de la Policía, de Política Interior y de Migraciones (BOE núm. 11, de 17 de junio de 1993). 
y la Federación Española de Municipios y Provincias (FEMP), firmando el Convenio Marco de Colaboración para la Ordenación de las Migraciones Interiores en las Diversas Campañas Agrícolas de Empleo Temporal. Según su propia Exposición de Motivos, el Convenio fue adoptado porque en los períodos de recolección y de ciertas faenas agrícolas se producían desplazamientos incontrolados de trabajadores que no podían ser absorbidos por las ofertas de empleo que se generaban, bien por desplazarse en fechas inadecuadas o bien por ser su volumen muy superior al necesario. Como consecuencia, las localidades de destino soportaban la afluencia de los mismos de forma muy precaria, al ser superadas las previsiones de atención de los servicios sociales y sanitarios. Así, el fin del Convenio era lograr una sintonía entre las necesidades de mano de obra de los empresarios y los trabajadores que se desplazaban, asignando para ello una serie de responsabilidades a cada una de las partes firmantes: habilitación de alojamientos para los jornaleros, coordinación y organización de sus desplazamientos, asesoramiento e información en materia sociolaboral, mantenimiento de guarderías y residencias infantiles en los lugares de origen y formación ocupacional (Cláusula 2).

Las medidas puestas en marcha no alcanzaron los resultados esperados, manteniéndose la insuficiencia de jornaleros. Esto dio lugar a que las partes firmantes del Convenio Marco de 1997 se volvieran a reunir el 21 de septiembre de 1999, adoptando un Protocolo Adicional a dicho Convenio. Éste se marcaba como objetivo «la colaboración en el establecimiento y desarrollo de un procedimiento subsidiario para la contratación de trabajadores extranjeros en sus países de origen, en campañas agrícolas de temporada, una vez agotadas las posibilidades de contratar trabajadores españoles, comunitarios o extranjeros legalmente establecidos en España» (Cláusula Primera). Esta medida pasaba a sumarse a las acordadas en el Convenio Marco. Se detallaba además que «la implantación del procedimiento de contratación de trabajadores extranjeros se irá desarrollando progresivamente, comenzando con experiencias piloto en zonas delimitadas»(Cláusula Cuarta). El primero de estos ensayos tuvo lugar en Lleida en el año 1999. Al año siguiente la experiencia se repitió en esta provincia y se extendió a las de Almería, Guadalajara y Tenerife, así como a la campaña fresera 2000/2011 de Huelva (Gordo, 2009).

La nueva Ley de Extranjería aprobada en el año 20004 incorporó los contenidos del Convenio Marco y su Protocolo Adicional, así como la figura del contingente, que hasta entonces sólo venía disfrutando de rango reglamentario. Otra de sus principales novedades fue el reconocimiento expreso de las actividades de temporada o campaña como un «régimen especial», señalando que el Gobierno regularía «reglamentariamente el permiso de trabajo para los trabajadores extranjeros en actividades de temporada o campaña que les permita la entrada y salida del territorio nacional de acuerdo con las características de las citadas campañas» (art. 41.1). Aclarar que la mencionada Ley de Extranjería ha sufrido diversas reformas, a pesar de lo cual el contingente de temporada ha mantenido la misma filosofía. Tras la aprobación de la Ley Orgánica $2 / 2009^{5}$ ha pasado a denominarse gestión colectiva de los contratos en origen.

4 Ley Orgánica 4/2000, de 11 de enero, sobre derechos y libertades de los extranjeros en España y su integración social (BOE de 12 de enero de 2000; corrección de errores en BOE de 24 de enero de 2000).

5 Ley Orgánica 2/2009, de 11 de diciembre, de reforma de la Ley Orgánica 4/2000, de 11 de enero, sobre derechos y libertades de los extranjeros en España y su integración social (BOE núm. 299, de 12 de diciembre de 2009). Su desarrollo reglamentario está recogido en el Real Decreto 557/2011, de 20 de abril, por el que se 
De este modo, los agricultores disponen de la mano de obra necesaria a través de la autorización de residencia temporal y trabajo por cuenta ajena de duración determinada. Ésta permite la realización de actividades o servicios de temporada o campaña y puede limitarse a una actividad y ámbito geográfico concreto. Su duración coincide con la del contrato de trabajo y no puede exceder de nueve meses, dentro de un periodo de doce meses consecutivos. La obtención de dicha autorización se inicia con la presentación de las ofertas de empleo por parte del empresario, o la organización empresarial a la que pertenezca, ante la Comisión Provincial creada en las Delegaciones y Subdelegaciones del Gobierno. Las ofertas de trabajo pueden ser genéricas o nominativas y deben presentarse tres meses antes de la fecha de inicio del trabajo temporal en cualquier sector de actividad ${ }^{6}$.

Cuadro 1

CUPO DE TEMPORADA POR SECTOR DE ACTIVIDAD DENTRO DE LOS ACUERDOS DE CONTINGENTE (2007 Y 2008)

\begin{tabular}{|c|c|c|c|c|c|c|c|c|}
\hline \multirow{3}{*}{ Sector de actividad } & \multicolumn{4}{|c|}{ PUESTOS OFERTADOS } & \multicolumn{4}{|c|}{$\begin{array}{l}\text { TRABAJADORES } \\
\text { SELECCIONADOS }\end{array}$} \\
\hline & \multicolumn{2}{|c|}{$2007(1)$} & \multicolumn{2}{|c|}{$2008(2)$} & \multicolumn{2}{|c|}{2007 (1) } & \multicolumn{2}{|c|}{$2008(2)$} \\
\hline & Total & $\%$ & Total & $\%$ & Total & $\%$ & Total & $\%$ \\
\hline Construcción & 86 & 0,12 & 14 & 0,02 & 86 & 0,13 & 14 & 0,03 \\
\hline Hostelería & 804 & 1,09 & 449 & 0,82 & 607 & 0,94 & 443 & 0,94 \\
\hline Transportes & 530 & 0,72 & 151 & 0,27 & 371 & 0,57 & 128 & 0,27 \\
\hline Comercio & 90 & 0,12 & 5 & 0,00 & 90 & 0,14 & 5 & 0,01 \\
\hline Agricultura & 71.092 & 96,76 & 53.101 & 96,74 & 62.938 & 97,25 & 45.681 & 96,82 \\
\hline Ind. Metal & 3 & 0,00 & 31 & 0,06 & 3 & 0,00 & 31 & 0,06 \\
\hline Ind. Textil y Confección & 0 & 0,00 & 0 & 0,00 & 0 & 0,00 & 0 & 0,00 \\
\hline Ind. Madera & 2 & 0,00 & 2 & 0,00 & 2 & 0,00 & 2 & 0,00 \\
\hline Ind. Alimentación & 3 & 0,00 & 208 & 0,38 & 3 & 0,00 & 208 & 0,44 \\
\hline Otras industrias & 110 & 0,15 & 26 & 0,05 & 110 & 0,17 & 26 & 0,05 \\
\hline Pesca & 2 & 0,00 & 0 & 0,00 & 2 & 0,00 & 0 & 0,00 \\
\hline Servicios & 751 & 1,02 & 903 & 1,64 & 504 & 0,78 & 642 & 1,36 \\
\hline TOTAL & 73.473 & 100,00 & 54.890 & 100,00 & 64.716 & 100,00 & 47.180 & 100,00 \\
\hline
\end{tabular}

Fuente: MTIN, 2008b (1) y 2009 (2). Elaboración: Gordo, 2011.

Pese a que prácticamente cualquier actividad de temporada puede acogerse a la gestión colectiva de los contratos en origen, en el cuadro 1 se puede comprobar que en el territorio español han sido las tareas agrícolas las que han monopolizando los contratos que se tramitan a través de esta vía de reclutamiento laboral. Aclarar que desde el año 2005, las Resoluciones que aprueban el contingente sólo publican el cupo autorizado con carácter estable. Las autorizaciones de temporada son aprobadas en función de la situación nacional de empleo del momento concreto en que son presentadas. «Esta decisión es bastante

aprueba el Reglamento de la Ley Orgánica 4/2000, sobre derechos y libertades de los extranjeros en España y su integración social, tras su reforma por Ley Orgánica 2/2009 (BOE núm. 103, de 30 de abril de 2011).

6 Véase en Gordo (2009) y Márquez y Gordo (2007) los requisitos que deben cumplir los empresarios y trabajadores para obtener una respuesta favorable a la petición. 
acertada, viniendo a ratificar las particularidades de las tareas de temporada, tanto en la agricultura como en el resto de sectores de actividad. En el caso concreto de la agricultura, no parece muy lógico que en diciembre, que es cuando ahora se acuerda el contingente, estén ya previstas las necesidades de mano de obra temporal para las campañas agrícolas del año siguiente. Hay que tener en cuenta que éstas pueden sufrir importantes oscilaciones en función de las condiciones climáticas e incluso de posibles plagas o enfermedades» (Gordo, 2009: 135).
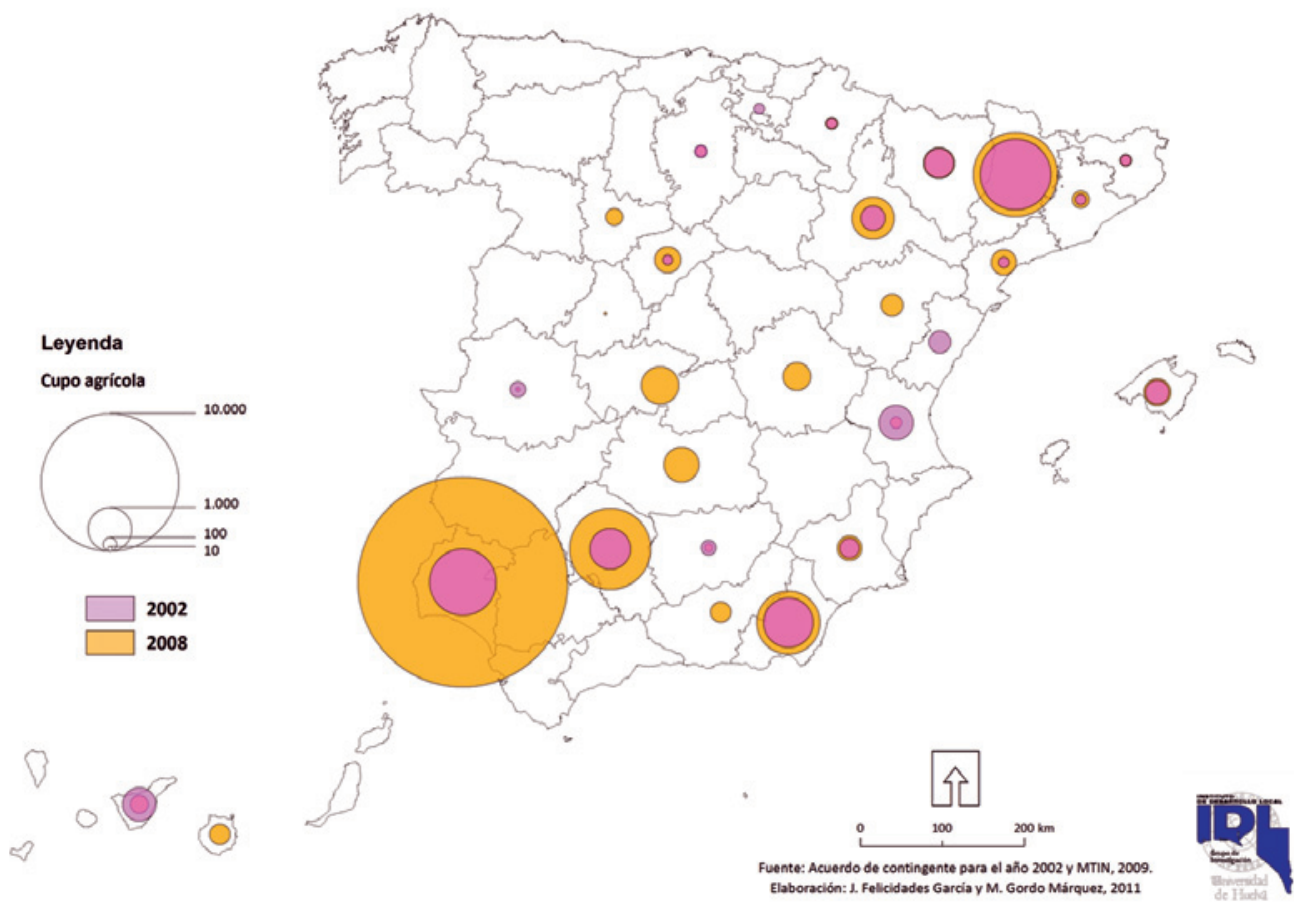

Fuente: Elaboración propia.

Por lo que se refiere a la implantación geográfica, decir que Lleida es, tras Huelva, la segunda provincia en importancia a la hora de contratar temporeros mediante la gestión colectiva de los contratos en origen (Figura 1). En el año 2008 fueron 4.843 los braceros que llegaron a Lleida por este procedimiento, frente a los 31.699 de la provincia onubense (MTIN, 2009). El actual contexto de crisis incide en que la Administración se muestre menos colaboradora a la hora de facilitar datos sobre esta cuestión, de ahí la imposibilidad de ofrecer una información más actualizada para el conjunto nacional. No obstante, los autores de este trabajo sí hemos mantenido una estrecha relación con la Subdelegación del Gobierno en 
Lleida, también con la de Huelva, lo que ha facilitado la investigación e información para los años posteriores y desde aquí le mostramos nuestro profundo agradecimiento ${ }^{7}$.

Las tareas que estos temporeros realizan en las campañas de Lleida son, básicamente, la recolección de fruta dulce, cereza, manzana, melocotón, nectarina y pera en los meses de primavera y verano, y la uva a partir de septiembre. No hay que olvidar que esta provincia, con 37.000 hectáreas de frutales, cultiva el $81 \%$ de la superficie de fruta dulce de Cataluña y más del $35 \%$ de la española, siendo pionera en el cultivo de melocotón y pera. La producción tiene un marcado carácter exportador y se aproxima a las 900.000 toneladas de fruta en una campaña normal (Pascual, 2010). Por otra parte, los recién construidos embalses de Oliana y Rialb aportan capacidad reguladora para aumentar las dotaciones de riego del Canal de Urgell y acometer las nuevas transformaciones de secano en regadío previstas, entre los que destacan el Canal Segarra-Garrigues y el Garrigues Baixes. La puesta en marcha de estas áreas de regadío permitirá incrementar el potencial productor del sector agrario de Lleida y creará sin duda nuevas necesidades de mano de obra temporal para determinadas tareas agrarias.

Según responsables del sindicato agrario Unió de Pagesos, del Departamento de Agricultura, Ganadería, Pesca, Alimentación y Medio Natural de la Generalitat y la Dependencia de Trabajo e Inmigración de la Subdelegación del Gobierno en Lleida, el número de temporeros necesarios para atender la campaña de fruta en esta provincia en una campaña normal es de aproximadamente 8.000 personas, teniendo en cuenta los que trabajan en la recolección y los que están en los almacenes y centrales. Hasta la campaña 2009 dicha mano de obra se venía repartiendo en partes iguales entre los trabajadores extranjeros contratados en origen y la contratación de trabajadores interiores, bien sean autóctonos o extranjeros. Así, unos 3.000 venían siendo jornaleros interiores, la gran mayoría extranjeros, y unos 1.000 eran familiares o gente próxima al agricultor.

A pesar del elevado número de temporeros contratados en origen, la tramitación de dichos contratos es compleja y no resulta barata para el empresario agrícola. En primer lugar, es necesario ir al país de origen para realizar la selección de candidatos conjuntamente con la Administración española y la del país en cuestión. Dicho trámite normalmente lo realiza la organización empresarial que aglutina a los diferentes empresarios. Posteriormente, se deben tramitar los visados para salir del país y entrar en España, y es necesario organizar el viaje de ida y vuelta y asumir parte de los gastos de transporte. El empleador también debe garantizar el alojamiento del temporero y no le puede cobrar más del $10 \%$ del salario por este concepto ${ }^{8}$.

Allepuz et al. (2009b) analizan la valoración de las contrataciones en origen por parte de los agricultores, entre ellos los de la zona de Lleida. Consideran que más que las condiciones de trabajo (salario, vacaciones, jornada laboral) las condiciones en las que se realiza el trabajo (al aire libre, fuerza física) son la principal causa que resta atractivo a las faenas agrícolas por parte de la población autóctona. Por el contrario, una de las ventajas de la contratación en origen de temporada es la seguridad que supone el disponer del número de trabajadores necesario en el momento oportuno y durante el tiempo necesario, estabilidad que se

7 Agradecimiento que también hacemos extensible al resto de agentes entrevistados.

8 En Lleida, Unió de Pagesos tiene censados cerca de 2.000 plazas de alojamiento de temporeros. Algunos de estos alojamientos están promovidos por los ayuntamientos de las zonas frutícolas, y otros por empresarios agrícolas particulares. 
garantiza en menor medida con otros sistemas de reclutamiento. A ello se une la posibilidad de contratar al trabajador durante campañas consecutivas, siempre y cuando cumplan con el compromiso de retorno a su país una vez finalizada la relación laboral. De esta forma se recupera la inversión en la formación de este capital humano.

\section{EL PERFIL DEL JORNALERO CONTRATADO EN ORIGEN POR LOS AGRICULTORES DE LLEIDA}

Como ha quedado expuesto en el epígrafe anterior, la primera experiencia piloto llevada a cabo en España de contratación de temporeros extranjeros en sus países de origen tuvo lugar en la provincia de Lleida, concretamente con la contratación en junio de 1999 de 35 hombres colombianos por el sindicato Unió de Pagesos. También se ha señalado que a partir del año 2000 la regulación de este sistema de reclutamiento laboral fue incorporada a la Ley de Extranjería. Ésta y su Reglamento han venido estableciendo que las ofertas de empleo tramitadas por esta vía se orientarán preferentemente hacia los países con los que España haya firmado acuerdos sobre regulación y ordenación de los flujos migratorios, insistiéndose expresamente en ello respecto al régimen especial de los trabajadores de temporada. En este sentido hay que señalar que el Programa Global de Regulación y Coordinación de la Extranjería y la Inmigración 2001 - 2004 (Programa GRECO) ${ }^{9}$ estableció los criterios para que el Gobierno adoptara convenios sobre inmigración al objeto de cubrir los puestos vacantes en la economía española. Colombia cumplía varios de estos criterios, como el ser una de las principales corrientes migratorias hacia España o mantener estrechos lazos históricos, políticos y económicos. Así, el 21 de mayo de 2001 se firmó el Acuerdo entre España y Colombia relativo a la regulación y ordenación de los flujos migratorios laborales, el cual entró en vigor en mayo de $2002^{10}$. Los restantes países con los que inicialmente se suscribió tales acuerdos, entre 2001 y 2003, son Bulgaria, Ecuador, Marruecos, Polonia, República Dominicana y Rumanía.

La Legislación de Extranjería establece que los países con Acuerdo tendrán carácter «preferente», pero no «obligatorio», por lo que los agricultores también pueden reclutar a sus trabajadores en otros lugares. Sin embargo la gran mayoría ha decidido limitarse a los considerados preferentes. La justificación de ello radica en que los convenios suscritos incluyen el compromiso para las autoridades de estos países de organizar el proceso de preselección de los trabajadores, de ahí que los empresarios tengan más facilidades a la hora de llevar a cabo la selección de los temporeros que quieren contratar (Gordo, 2011). En el caso de los colombianos que llegan a Lleida existe una facilidad añadida, pues para la experiencia piloto de 1999 Unió de Pagesos había contactado con la ONG colombiana TierraUNA, creando conjuntamente el Programa de Temporeros Campesinos Colombianos en España. A través del mismo se seleccionaron los trabajadores en función de los criterios marcados por el sin-

9 Resolución de 17 de abril de 2001, de la Delegación del Gobierno para la Extranjería y la Inmigración, por la que se dispone la publicación del Acuerdo del Consejo de Ministros del día 30 de marzo de 2001, por el que se aprueba el Programa Global de Regulación y Coordinación de la Extranjería y la Inmigración (BOE núm. 101, de 27 de abril de 2001).

10 Entrada en vigor del Acuerdo entre España y Colombia relativo a la regulación y ordenación de los flujos migratorios laborales, hecho en Madrid el 21 de mayo de 2001, cuya aplicación provisional fue publicada en el «Boletín Oficial del Estado» número 159, de fecha 4 de julio de 2001 (BOE núm. 111, de 9 de mayo de 2002). 
dicato. Desde entonces TierraUNA mantiene el rol de protagonista en el proceso de selección de trabajadores colombianos para diversas organizaciones agrarias españolas, entre ellas Unió de Pagesos de Cataluña.

La selección tiene lugar en más de 50 municipios de 12 departamentos de Colombia, favoreciendo a campesinos de escasos recursos y zonas muy pobres o que han padecido alguna clase de desastre. El Programa promueve el retorno y fomenta el compromiso social de generar cambios positivos, potenciando la localidad de origen como una opción de desarrollo y bienestar, donde vale la pena quedarse y desarrollar planes de vida sostenibles propios y para los demás que no tienen la oportunidad de salir del país, vinculando en estas propuestas a las organizaciones receptoras de los trabajadores temporales. En ese sentido, Unió de Pagesos creó en el año 2001 la fundación Pagesos Solidaris. Entre sus objetivos destaca el fomento de unas relaciones justas entre las sociedades agrarias y el refuerzo de la solidaridad entre agricultores de diferentes países, el acompañamiento de la población que llega a Cataluña para trabajar temporalmente en las campañas de recolección y manipulación de fruta, dándoles apoyo durante su estancia en Cataluña y en su país de origen. A tal fin ofrecen formación a los peones contratados en origen ${ }^{11}$, para que se conviertan en agentes de desarrollo cuanto retornen a su país de procedencia. Además impulsa proyectos de desarrollo agrarios en Colombia, como iniciativas ganaderas, de mejora de la vivienda, creación de micro-empresa, dotación de agua potable y tratamiento de aguas residuales, etc. En este sentido hay que subrayar que existe una relación directa entre el lugar de origen de los temporeros, región o departamento, y las zonas en las que se llevan a cabo dichos proyectos de desarrollo.

Cuadro 2

CONTINGENTE DE TEMPORADA AUTORIZADO A TRABAJAR EN LA CAMPAÑA DE LA FRUTA EN LLEIDA, SEGÚN PAÍS DE ORIGEN (2005-2012)

\begin{tabular}{|l|c|c|c|c|c|c|c|c|}
\hline País de origen & $\mathbf{2 0 0 5}$ & $\mathbf{2 0 0 6}$ & $\mathbf{2 0 0 7}$ & $\mathbf{2 0 0 8}$ & $\mathbf{2 0 0 9}$ & $\mathbf{2 0 1 0}$ & $\mathbf{2 0 1 1}$ & $\mathbf{2 0 1 2}$ \\
\hline Rumanía & 3.182 & 3.376 & 5.512 & 3.901 & 0 & 0 & 0 & 212 \\
\hline Colombia & 600 & 796 & 1.098 & 835 & 777 & 603 & 501 & 371 \\
\hline Polonia & 3 & 0 & 0 & 0 & 0 & 0 & 0 & 0 \\
\hline Marruecos & 2 & 12 & 127 & 68 & 13 & 12 & 10 & 10 \\
\hline Bolivia & 0 & 15 & 16 & 16 & 14 & 12 & 8 & 0 \\
\hline Bulgaria & 0 & 0 & 13 & 12 & 0 & 0 & 0 & 0 \\
\hline Perú & 0 & 0 & 25 & 0 & 1 & 1 & 0 & 0 \\
\hline Senegal & 0 & 0 & 50 & 11 & 46 & 24 & 20 & 20 \\
\hline Honduras & 0 & 0 & 0 & 0 & 9 & 27 & 0 & 15 \\
\hline TOTAL & 3.787 & 4.199 & $6.846^{*}$ & 4.843 & 860 & 679 & 539 & $628^{* *}$ \\
\hline
\end{tabular}

Fuente: Dependencia de Trabajo e Inmigración de la Subdelegación del Gobierno en Lleida. Elaboración propia.

* Este año los rumanos ya gozaban de la ciudadanía de la UE y podían circular libremente por España, aunque ello no comportaba autorización para trabajar. El resultado fue que aproximadamente un $43 \%$ de las autorizaciones no se hicieron efectivas, debido a que los trabajadores no se presentaron a las empresas frutícolas leridanas.

** El Gobierno restableció la moratoria a la libre circulación laboral de los ciudadanos rumanos y búlgaros y podían volver a ser contratados por el procedimiento de la gestión colectiva de los contratos en origen.

11 Por ejemplo, en el año 2007 Pagesos solidaris formó en origen a 600 colombianos y a 150 rumanos que trabajaron en la campaña agrícola de ese año. 
Motivos de cercanía geográfica explican por qué los temporeros rumanos han sido los más demandados en Lleida (Cuadro 2). No hay que perder de vista que en este procedimiento la empresa, o la patronal a la que pertenezca ésta, queda obligada a organizar los viajes de llegada del trabajador a España y de regreso al país de origen y asumir, como mínimo, el coste del primero de tales viajes y los gastos de traslado de ida y vuelta entre el puesto de entrada a España y el lugar del alojamiento. Por tanto, traer a un jornalero desde Colombia resulta muy oneroso para el empresario, al menos en comparación con otras alternativas europeas o africanas. Este mismo argumento debería poderse aplicar para el caso de Bulgaria, pero el convenio con este país se retrasó hasta 2003, lo que jugó en contra de sus nacionales, pues los empresarios prefirieron seguir apostando por las canteras laborales que ya conocían. En el caso de Polonia, su inminente entrada en la UE contribuyó a que fuera un mercado prácticamente inexplorado. Marruecos, pese a su cercanía, ha tenido en contra los prejuicios sobre sus nacionales, lo que ha desincentivado su contratación, al igual que inicialmente sucedió en la provincia de Huelva (Gordo, 2011).

El interés por contratar a temporeros colombianos para la fruticultura leridana responde en buena medida a los lazos establecidos con los organismos del país de procedencia, en concreto entre la ONG colombiana TierraUNA y Unió de Pagesos. También está presente el compromiso con el codesarrollo, y la financiación que reciben estas entidades por sus proyectos. La contratación de trabajadores colombianos minimiza las dificultades relacionadas con determinados aspectos como el idioma, la cultura, la experiencia en el sector agrario y otros aspectos como la religión. Por otra lado, desde 1999 una parte de estos temporeros colombianos repite cada año, lo cual permite recuperar la formación y el conocimiento (situación de las fincas, técnicas de recolección, etc.) adquiridos en campañas anteriores. Si bien estas razones los hacen atractivos en cuento a la nacionalidad, los motivos geográficos llevarían a descartarlos, pues los costes de su traslado les restarían atractivo, como ocurre en otras zonas agrarias del territorio español ${ }^{12}$.

Desde hace varios años Administración, patronal y sindicatos vienen defendiendo una fórmula para, entre otras cuestiones, reducir los gastos de desplazamiento que tienen que asumir los empresarios agrarios. Se trata de la concatenación de campañas agrícolas, la cual fue incorporada a la Ley de Extranjería. Implica que los costes de traslado del trabajador sean repartidos entre los distintos agricultores que lo van a tener contratado, lo que hace más atractivo la contratación en Colombia u otros países latinoamericanos. Los jornaleros también se ven beneficiados por esta iniciativa, pues pueden ampliar sus contratos hasta un máximo de 9 meses, lo que implica poder aumentar sus ingresos, aspecto nada desdeñable habida cuenta de que tienen que abonar buena parte del viaje de regreso a su país. No obstante sigue siendo una opción muy poco utilizada, en particular por la dificultad de cuadrar el fin de una campaña y el comienzo de la siguiente. Así, según los datos facilitados por la Dependencia de Trabajo e Inmigración de la Subdelegación del Gobierno en Lleida, en el año 2008 llegaron a esta provincia 46 temporeros concatenando la campaña de Huelva.

12 Véase Márquez y Gordo (2007) para el caso de los temporeros contratados en la zona de Huelva. 
La adhesión de Polonia, Bulgaria y Rumanía a la UE ha tenido repercusiones en el mapa de países considerados prioritarios. Una vez que los nacionales de estos Estados se han convertido en ciudadanos comunitarios de pleno derecho ${ }^{13}$, han dejado de regirse por la Legislación de Extranjería, de ahí que dejaran de figurar en las estadísticas de los contingentes (Cuadro 2). Ahora están regulados por el Régimen Comunitario, mucho más beneficioso, el cual los equipara a los españoles. En un intento de «compensar estas bajas» y aumentar las alternativas de la inmigración selectiva por países, el Acuerdo que reguló el contingente para el año $2008^{14}$ estableció que las ofertas de empleo se cursarían «preferentemente a los países con los que España tiene suscritos acuerdos sobre regulación y ordenación de flujos migratorios o, subsidiariamente, instrumentos de colaboración en esta materia» (Apartado 4.3). Las Instrucciones dictadas en desarrollo de este contingente ${ }^{15}$ insistían en ello, detallando los países con los que se habían firmado tales instrumentos de colaboración y que, por tanto, pasaban a ser preferentes: El Salvador, Honduras, Perú, Senegal, Argentina y Filipinas (Apartado Decimocuarto). No obstante, para el caso de Argentina se puntualizaba que sólo se podrían tramitar ofertas para puestos de socorristas y a Filipinas únicamente se podían dirigir ofertas del sector sociosanitario. La búsqueda de nuevas canteras laborales no ha cesado. Según la Orden ESS/1/2012, de 5 de enero, por la que se regula la gestión colectiva de contrataciones en origen para $2012^{16}$, los países con los que España tiene suscritos acuerdos sobre regulación y ordenación de flujos migratorios son: Colombia, Ecuador, Marruecos, Mauritania, Ucrania y República Dominicana. Por su parte, con los que mantiene instrumentos de colaboración en esta materia son: Gambia, Guinea, Guinea Bissau, Cabo Verde, Senegal, Mali, Níger, México, El Salvador, Filipinas, Honduras, Paraguay y Argentina (art. 8.2).

En cuanto al género (Cuadro 3), en la fruticultura leridana predomina la mano de obra masculina, debido a que los agricultores comparten la opinión que el tipo de trabajo a desarrollar en sus explotaciones requiere una elevada fuerza física, por la dureza de las tareas a desarrollar y las condiciones climáticas bajo las que se realizan, básicamente en los meses de más calor. La excepción es el colectivo marroquí, numéricamente poco significativo, pero que presenta la particularidad de que está íntegramente formado por mujeres. Honduras muestra una mayor equiparación por sexos, pero su volumen de contratación es también muy bajo. Por lo general, con independencia de la nacionalidad, las féminas se dedican a tareas de almacenaje de la fruta.

13 La moratoria a la libertad de circulación laboral para Polonia expiró el 1 de mayo de 2006, mientras que para Bulgaria y Rumanía lo hizo inicialmente el 1 de enero de 2009.

14 Resolución de 26 de diciembre de 2007, de la Secretaría de Estado de Inmigración y Emigración, por la que se dispone la publicación del Acuerdo de Consejo de Ministros, de 21 de diciembre de 2007, por el que se regula el contingente de trabajadores extranjeros de régimen no comunitario en España para el año 2008 (BOE núm. 11, de 12 de enero de 2008).

15 Instrucciones DGI/SGGCFM/03/2008, dictadas en desarrollo del Acuerdo del Consejo de Ministros, de 21 de diciembre de 2007, por el que se regula el contingente de trabajadores extranjeros de régimen no comunitario en España para el año 2008. Fueron adoptadas el 24 de marzo de 2008 y los errores detectados se corrigieron el 2 de abril de este mismo año. Al igual que en los últimos años, estas Instrucciones no han sido publicadas en el BOE.

16 BOE núm. 5, de 6 de enero de 2012. 
Cuadro 3

PERFIL DEL CONTINGENTE DE TEMPORADA 2010 (\%)

\begin{tabular}{|c|c|c|c|c|c|c|c|c|c|c|}
\hline & \multicolumn{2}{|c|}{ Sexo } & \multicolumn{3}{|c|}{ Edad } & \multicolumn{5}{|c|}{ Estado civil } \\
\hline País de origen & $\mathbf{H}$ & $\mathbf{M}$ & $>40$ & $31-40$ & $30-20$ & Sol. & Cas. & Divo. & Viud. & Sin datos \\
\hline Colombia & 85 & 15 & 26 & 46 & 28 & 11 & 22 & 0,3 & 0 & 67 \\
\hline Marruecos & 0 & 100 & 50 & 50 & 0 & 0 & 33 & 42 & 17 & 8 \\
\hline Bolivia & 100 & 0 & 58 & 25 & 16 & 58 & 0 & 0 & 0 & 42 \\
\hline Perú & 100 & 0 & 100 & 0 & 0 & 100 & 0 & 0 & 0 & 0 \\
\hline Senegal & 100 & 0 & 0 & 58 & 42 & 46 & 38 & 0 & 0 & 16 \\
\hline Honduras & 55 & 45 & 13 & 55 & 32 & 42 & 21 & 0 & 0 & 37 \\
\hline
\end{tabular}

Fuente: Dependencia de Trabajo e Inmigración de la Subdelegación del Gobierno en Lleida. Elaboración propia, 2012.

Los temporeros son en buena medida repetidores. Es decir, llegan mediante una oferta nominativa por haber participado en campañas anteriores y haber cumplido con el compromiso de retorno a su país de origen una vez finalizada la relación laboral. En el caso de los colombianos, la larga duración de sus contratos (generalmente entre 6 y 9 meses) y la posibilidad de volver a trabajar al poco tiempo contribuyen notablemente al retorno y, por tanto, al hecho de ser repetidores. El agricultor los demanda porque está satisfecho con su rendimiento laboral, y también con su carácter poco reivindicativo. Además, así recupera la inversión en la formación de este capital humano (situación de las fincas, técnicas de recolección, etc.).

En relación a la edad, destacar que todos los temporeros superan los 20 años. La franja de edad 31-45 concentra la mayor demanda, lo cual muestra que la experiencia y la fortaleza física es un factor a tener en cuenta. Por lo que se refiere al estado civil, es un dato que no se suele registrar en las estadísticas oficiales.

\section{LA SITUACIÓN ANTE EL ESCENARIO DE RECESIÓN ECONÓMICA}

El nuevo escenario económico que se inicia a partir de 2008 con la entrada en recesión de la economía española no ha modificado la necesidad de mano de obra temporal en el sector agrícola. Sin embargo, se han producido importantes recortes en el volumen de trabajadores contratados mediante la gestión colectiva de los contratos en origen como se muestra en el Cuadro 2, pues la Administración y los sindicatos agrarios, como Unió de Pagesos o Joves Agricultors i Ramaders de Catalunya, han apostado por dar preferencia a los trabajadores en situación de desempleo que se encuentran en España, al objeto de que sean ellos los que realicen las tareas de recolección de las campañas de fruta. Hay que tener en cuenta que la actual coyuntura económica se caracteriza por una importante destrucción del empleo y, como se señaló en el apartado 4, el hecho de que la política de extranjería esté articulada en torno a la protección del trabajador nacional, comunitario y otros extranjeros residentes en España, hace que se dé prioridad a éstos a la hora de acceder al mercado de trabajo. De esta forma, el contingente se reduce en un intento de limitar 
la llegada de nuevos efectivos laborales, a fin de evitar la competencia en el empleo, ya que una parte de los trabajadores españoles, y de los extranjeros residentes en el país, están regresando al campo ante la falta de expectativas en otros sectores ${ }^{17}$.

Así, ante una situación económica que tras varios años de recesión sigue ofreciendo pocas oportunidades de ocupación, algunos trabajadores parados han puesto la vista en las actividades hortofrutícolas, que siguen precisando mano de obra. El sector agrario se convierte en refugio laboral, donde acuden a buscar empleo trabajadores afectados por la crisis en otros sectores. Este mayor número de activos agrarios reduce las posibilidades de la contratación de temporeros extranjeros en sus países de origen. No obstante, los empresarios agrícolas leridanos prefieren a estos últimos por ser una mano de obra que ofrece una mayor estabilidad durante los meses de recogida de la fruta, lo cual garantiza la recolección de la cosecha. Según declaraciones de los sindicatos agrarios más representativos de la fruticultura leridana, Unió de Pagesos y Joves Agricultors i Ramaders de Catalunya, sólo este sistema de reclutamiento les garantiza la mano de obra que necesitan, ya que recurrir a los parados residentes en Lleida, ya sean extranjeros o no, les puede acarrear problemas a los que las explotaciones y los agricultores no se pueden exponer. Confían más en los contratados en origen, puesto que tienen experiencia en este tipo de trabajos, están formados y llegan mentalizados para su tarea.

Pese a ello la Administración ha adoptado medidas para fomentar la empleabilidad de los parados españoles y extranjeros residentes en el país. En este sentido, el Servicio Catalán de Ocupación (SOC) ha venido informando a los parados de la región sobre las posibilidades laborales que ofrecen las campañas de fruta de Lleida, para incentivar su ocupación como temporeros. Las misivas enviadas para sondear la posibilidad de trabajar en la campaña de fruta de 2009 superaron las 9.000, de las que 2.800 fueron contestadas afirmativamente. Sin embargo, las ofertas agrarias a cubrir en toda Cataluña ascendían a 6.200, con lo que la contratación de trabajadores en sus países origen también fue necesaria. Los esfuerzos de la intermediación laboral llevada a cabo por la Administración se redoblaron para la campaña de 2010, enviándose unas 17.000 cartas a trabajadores en paro. Sin embargo, la respuesta fue aún mucho más negativa, pese a lo cual se redujo la contratación en origen (Cuadro 2). Los datos indican que ni siquiera la creciente tasa de desempleo motivó a los trabajadores situados en el país a participar en estas campañas de recolección de fruta de manera significativa. Los bajos salarios, la dureza del trabajo, las coberturas sociales como el subsidio por desempleo, o la sobreeducación para realizar trabajos no cualificados fueron algunos de los motivos de rechazo.

En 2011 el SOC modificó su planteamiento de la campaña y eliminó el envío de cartas a los parados, ante la poca respuesta obtenida durante los dos últimos ejercicios. Es por ello que la Generalitat dio paso a un sistema de orientación personalizado dentro del programa Prepárate, el cual preveía una beca de seguimiento para aquellos trabajadores que querían mejorar su empleabilidad. Otra importante novedad de esa campaña es que no se autorizaron las ofertas genéricas para la gestión colectiva de las contrataciones en origen, únicamente las nominativas, de manera que sólo participaron los temporeros que ya tenían un derecho consolidado por haber venido dos años a trabajar a Lleida. Un tercer hito a destacar en 2011 fue

17 Al respecto véase Márquez et al. (2011). 
que el Gobierno español restableció la moratoria a la libre circulación laboral de los ciudadanos rumanos y búlgaros, de manera que nuevamente se rigieron por la Ley de Extranjería para cuestiones laborales y podían volver a ser contratados por el procedimiento de la gestión colectiva de los contratos en origen. No tuvo efectos en la campaña de ese año, pero sí en la de 2012, con 212 contrataciones, lo cual seguramente ha conllevado un desplazamiento de otras nacionalidades, dado el interés que los empresarios han venido mostrando por ellos (Cuadro 2).

En la campaña de fruta del año 2012 se generó una ocupación de 6.000 personas, de las que un $10 \%$ procedían de los contratos en origen de temporada, básicamente de trabajadores colombianos y rumanos. Igual que ocurrió durante la temporada pasada, se trataba de trabajadores repetidores que ya llevaban muchas campañas en Lleida. El resto de empleo se cubrió prácticamente en su totalidad por trabajadores extranjeros que llevaban tiempo viviendo en el país y perdieron su empleo en otros sectores, en especial la construcción. De estos, más de un $90 \%$ son extranjeros con nacionalidad o residencia en España, por lo que la cifra de temporeros autóctonos continua siendo pequeña a pesar de la voluntad y las gestiones de la Administración. Así pues, en las campañas de recolección de la fruta de 2011 y 2012 se contrataron menos temporeros en origen para dar prioridad a los trabajadores que estaban en paro en España, y no se incorporaron nuevas contrataciones en origen excepto la de aquellos trabajadores que habían adquirido este derecho legal por haber trabajado durante las dos campañas anteriores: son los jornaleros repetidores que llegan mediante ofertas nominativas.

En la campaña de 2013 se redujo la contratación de los trabajadores no comunitarios. La Subdelegada del Gobierno en Lleida anunció que se limitaría de nueve a siete meses el periodo de contratación en origen de temporada de ciudadanos extranjeros para trabajar en la campaña de recogida de fruta de las comarcas de Lleida. La medida responde al objetivo de priorizar la contratación de mano de obra interior en el caso de que los agricultores necesiten trabajadores. De esta forma, la contratación en origen actualmente sólo representa el 0,5\% del total de temporeros contratados en la campaña de recogida de la fruta.

$\mathrm{Al}$ respecto, los agricultores que contratan temporeros en origen muestran su disconformidad puesto que deberán contratar otros trabajadores para el periodo restante de dos meses, con el consiguiente incremento de los costes de gestión laborales por parte de la empresa agrícola. Las explotaciones frutícolas siguen confiando en la contratación en origen como mecanismo para garantizar las necesidades de mano de obra temporal durante la campaña de recolección de fruta, a pesar de las elevadas cifras de parados nacionales y el repunte de demanda de estos trabajadores en la campaña de 2012.

A semejanza de lo que ocurre en otras zonas agrarias como Andalucía, en Lleida desde el año 2008 se está produciendo un progresivo trasvase de mano de obra extranjera desempleada hacia el sector agrario. Escobar et al. 2012 afirman que el empleo agrario se ha convertido en estos tiempos de crisis, en un refugio para los desempleados extranjeros procedentes de otras actividades, detectándose un proceso de movilidad ocupacional descendente, que invierte la tendencia registrada durante el pasado ciclo de crecimiento económico. El estudio de Miguélez (2013) destaca, también, que la crisis ha provocado una movilidad ocupacional descendiente en España, donde el 15\% de los extranjeros ha bajado de categoría en su ocupación durante el periodo 2007-2011, mientras que entre los españoles el descenso de categoría ocupacional sólo es del 9,6\%. Esta pérdida de categoría laboral genera una mayor 
vulnerabilidad para posicionarse en el mercado de trabajo y empeora las perspectivas de inserción de los desocupados, lo cual genera una fractura entre la población autóctona y la inmigrante.

\section{CONCLUSIONES}

La carencia de mano de obra suficiente para atender las tareas del campo impuso la aprobación del contingente, hoy conocido como gestión colectiva de los contratos en origen, un mecanismo de reclutamiento laboral que ha permitido contratar como jornaleros a personas extranjeras no comunitarias que se encuentran en sus países. Éstos llegan mediante un procedimiento específico para las actividades de temporada, el cual contempla plazos especiales de tramitación, acordes con las particularidades de las campañas. El trabajador es contratado en función de las necesidades del empresario, en base a lo que se conoce como situación nacional de empleo, de manera que no supone una competencia para el jornalero español ni para otros extranjeros que ya residen en el país. Esto explica por qué en el contexto socioeconómico que actualmente atraviesa España, caracterizado por un importante desempleo, los cupos autorizados se han reducido considerablemente, aunque siguen aprobándose para sacar adelante las cosechas en provincias como Huelva y Lleida, por poner los dos ejemplos más importantes.

Tras la provincia de Huelva, Lleida es la que más jornaleros contrata mediante este sistema de reclutamiento laboral, destinándose básicamente a la recolección de fruta dulce, cereza, manzana, melocotón, nectarina y pera en los meses de primavera y verano, y la uva a partir de septiembre. Una de las ventajas de este procedimiento contractual es la estabilidad que supone el disponer del número de trabajadores necesario durante la campaña, y con experiencia en actividades del ámbito rural.

El perfil de trabajador demandado por el agricultor leridano se caracteriza por un predominio de la mano de obra masculina, dado lo duro del trabajo. En cuanto a la nacionalidad, las preferencias se han centrado en rumanos y colombianos, básicamente por razones económicas, culturales y de facilidad a la hora de hacer la selección en los países de origen. Rumanía, al adherirse a la UE y adquirir la plena libertad de circulación laboral quedó fuera de la gestión colectiva de las contrataciones en origen, de ahí que dejara de aparecer en las estadísticas oficiales hasta 2012, lo que no implica que no se siga contratando allí. Esto ha reforzado el peso relativo de Colombia, aunque en cifras absolutas el volumen contratado es similar e incluso se viene reduciendo en los últimos años con motivo de la coyuntura económica (Cuadro 2), en aras a dar prioridad a los desempleados locales, ya sean nacionales u extranjeros.

El reclutamiento de temporeros colombianos para trabajar en el campo de Lleida se inicia con la experiencia piloto de 1999 y se ha mantenido con menor o mayor intensidad hasta la actualidad. La existencia de una organización en el país de origen que facilita el proceso de selección de trabajadores, como el Programa de Temporeros Campesinos Colombianos en España, supone una ventaja para los empresarios agrícolas de Lleida, al evitar su desplazamiento hacia Colombia para realizar el reclutamiento.

Otro de los motivos se debe a que se han establecido lazos entre los organismos del país de procedencia, Colombia, y de destino que participan en el proceso de contratación. En 
concreto entre la organización no gubernamental colombiana TierraUNA y Unió de Pagesos. Estos lazos se han articulado a través de programas de formación, para que los temporeros contratados en origen se conviertan en agentes de desarrollo en cuanto retornen a Colombia. Al mismo tiempo, dichos organismos han impulsado proyectos de desarrollo agrarios en los países de origen. Principalmente Colombia, y en menor medida Marruecos y Bolivia.

Los esfuerzos de intermediación laboral llevados a cabo por las administraciones catalanas para impulsar la empleabilidad de los parados en las actividades de recolección de fruta se han saldado con insuficientes resultados, lo cual ha llevado a que actualmente se reduzca a siete meses el contrato para los trabajadores no comunitarios. Estas tareas siguen sin resultar atractivas, pese al desempleo. Por su parte, los empresarios agrarios prefieren la contratación en origen, pues les ofrece mayores garantías: asegura la mano de obra necesaria a lo largo de la campaña de recogida de fruta y el empleado tiene la experiencia necesaria para este tipo de puestos, pues en muchos casos son trabajadores que ya han sido contratados en ejercicios anteriores.

\section{BIBLIOGRAFÍA}

ACHÓN, O. (2011): Contratación en origen e institución total. Estudio sobre el sistema de alojamiento de trabajadores agrícolas extranjeros en el Segrià (Lleida). Tesis doctoral inédita. Barcelona. Universidad de Barcelona.

ALLEPUZ, R., FARRÉ, M., SALA, M. y TORRES, T. (2009a): La contractació en origen a Catalunya. Lleida. De París.

ALLEPUZ, R., FARRÉ, M., SALA, M. y TORRES, T. (2009b): «Eficàcia de la contractació en origen per a la inserció laboral de la població estrangera a Catalunya en un context de creixement econòmic. Aportacions per a un debat» en Recerca i Immigració II (Secretaria per a la Immigració del Departament d'Acció Social i Ciutadania de la Generalitat de Catalunya). Barcelona, Generalitat de Catalunya, 15-36.

CABRÉ, J. (2010): «El pes del sector fruiter a les terres de ponent» en L'Agricultura a les Terres de Lleida en el segle XXI (Babot, D. et al.). Lleida, Ed. La Mañana, 21-34.

DÍAZ, J. (2009): «Los campos que otros trabajan. Las campañas agrícolas españolas con mayor porcentaje de extranjeros» en Explorando los contratos en origen en los campos españoles (Gordo, M. y Felicidades, J., eds.). Huelva, Universidad de Huelva, 25-66.

ESCOBAR, M. S., GALERA, A. G. y BERMÚDEZ, A.(2012): La evolución del empleo agrario en Andalucía a partir del inicio de la crisis: ¿el fin del jornalero inmigrante? Bilbao. Actas del VII Congreso Migraciones Internacionales en España.

ETXEZARRETA, M. (1994): «Trabajo y agricultura: los cambios del sistema de trabajo en una agricultura en transformación». Agricultura y Sociedad, $\mathrm{n}^{\circ} 72,121-166$.

GORDO, M. (2009): «Implantación de los contratos en origen en las campañas agrícolas de temporada: el liderazgo de la provincia onubense» en Explorando los contratos en origen en los campos españoles (Gordo, M. y Felicidades, J., Eds.). Huelva, Universidad de Huelva, 119-144.

GORDO, M. (2011): «Los contratos en origen de temporada a las «marroquinas»: estrategia empresarial para sustituir a las trabajadoras del Este de Europa tras la incorporación de estos países a la UE» en Cooperación transfronteriza Andalucía-Algarve-Alentejo 
(Márquez, J. A. y Gordo, M., Eds). Huelva, Actas del XI Congreso de la Asociación Andaluza de Ciencia Regional de Andalucía 2009. Universidad de Huelva, 573-593.

MÁRQUEZ, J.A., GORDO, M., FELICIDADES, J. y DÍAZ J. (2011): Evolución de los contingentes de trabajadores extranjeros en España (1993-2011): las actividades agrícolas. Granada. Actas del XII Congreso de la Asociación Andaluza de Ciencia Regional.

MÁRQUEZ, J.A. y GORDO, M. (2007): «Temporeros extranjeros en Huelva (España) con contratos en origen: colombianos y ecuatorianos» en Orbis incognitvs: avisos y legajos del Nuevo Mundo: homenaje al profesor Luis Navarro García (Navarro, F., Coord.). Huelva, Universidad de Huelva, 765-779.

MIGUÉLEZ, F. (Dir.) (2013): Nuevas estrategias para la inmigración: recualificación para un nuevo mercado de trabajo: objetivos y conclusiones. Barcelona. Jornada sobre «Inmigración en un nuevo mercado de trabajo: políticas y estrategias». Caixaforum.

MTIN, Ministerio de Trabajo e Inmigración (2008a): Contingente 2007. Sector agrícola. Gestión de ofertas de carácter temporal. Año 2007 (ejecución a 19/2/2008). Documentación interna.

MTIN, Ministerio de Trabajo e Inmigración (2008b): Contratación en origen para actividades de temporada. Acuerdo de contingente 2007. Datos a 20 de noviembre de 2008. Documento interno. Inédito.

MTIN, Ministerio de Trabajo e Inmigración (2009): Contingente 2008. Gestión de ofertas de carácter temporal. Sector agrícola. Datos a 6 de mayo de 2009. Documentación interna. Inédito.

PASCUAL, M. (2010): «La fructicultura a Lleida» en L'Agricultura a les Terres de Lleida en el segle XXI. (Babot, D. et al.). Lleida, La Mañana, 35-52. 